\title{
A PEDAGOGIA dO ESTÉTICO NA FORMAÇÃO DOCENTE: UMA PROPOSTA DE (RE)(DES) CONSTRUÇÃO DE CONCEITOS SOBRE FAMÍLIAS
}

\author{
THE PEDAGOGY OF THE AESTHETIC IN TEACHER \\ EDUCATION: A PROPOSAL OF (RE)(DES)CONSTRUCTION OF \\ CONCEPTS ABOUT FAMILIES
}

\section{LA PEDAGOGÍA DEL ESTÉTICO EN LA FORMACIÓN DOCENTE: UNA PROPUESTA DE (RE)(DES)CONSTRUCCIÓN DE CONCEPTOS SOBRE FAMILIAS}

\author{
Isaias Batista de Oliveira Júnior ${ }^{1}$ \\ Universidade Estadual do Paraná, Professor do Curso de Pedagogia
}

Resumo: Neste texto o objetivo é problematizar o conceito de família ideal e família desestruturada de professores da educação básica da rede pública de ensino. Para atender ao objetivo proposto, traz-se o recorte de uma pesquisa de doutoramento, na qual elaborou-se, desenvolveu-se e aplicou-se uma proposta de formação para 15 docentes da educação básica. A metodologia consistiu na transmissão de obras fílmicas, em um total de oito encontros, cuja temática central era famílias não convencionais. Durante a intervenção aplicamos de forma individual um conjunto de instrumentos para coleta de dados, no entanto, neste artigo enfatizam-se os resultados obtidos mediante aplicação do inventário com ênfase no trabalho de Associação Livre de Palavras (ALP), o qual foi proposto no primeiro e no último encontro. Os dados obtidos foram categorizados com o auxílio do software EVOC e discutidos com base na Teoria das Representações Sociais (TRS), com apoio da Teoria do Núcleo Central (TNC). Concluiu-se que o cinema associado a outras estratégias que problematizem o conceito de família possibilita mobilizar e ressignificar sentidos associados aos conceitos de família ideal e família desestruturada.

Palavras-chave: Formação docente. Cinema. Representações sociais. Famílias organizadas em modelos não convencionais.

\footnotetext{
${ }^{1}$ Doutor em Educação pela Universidade Estadual Paulista Júlio de Mesquita Filho; Mestre em Educação pela Universidade Estadual de Maringá.
} 
Abstract: This text aims at problematizing the concept of ideal family and unstructured family from Elementary school's teachers of the public system. In order to meet the proposed objective, we bring a doctoral research, in which we elaborated, developed and applied a training proposal for 15 teachers from Elementary schools. The methodology consisted in the transmission of movies, in a total of eight meetings, with a central theme on non-conventional families. During the intervention we applied an individual set of instruments for data gathering, however, at this moment we will emphasize the results obtained by applying the inventory with emphasis on the Free Word Association (ALP) work, which was proposed in the first and in the last meeting. The data obtained were categorized with the help of EVOC software and discussed based on the Theory of Social Representations (TRS), with the support of the Central Nucleus Theory (TNC). We concluded that cinema associated with other strategies that problematize the concept of family makes it possible to mobilize and resignify meanings associated to the concepts of ideal family and unstructured family.

Keywords: Teacher training. Cinema. Social representations. Families organized in non-conventional models.

Resumen: Este texto tiene el objetivo de problematizar el concepto de familia ideal y familia desestructurada de profesores de la educación básica de la red pública de enseñanza. Para atender al objetivo propuesto, traemos el recorte de una investigación de doctorado, donde elaboramos, desarrollamos y aplicamos una propuesta de formación para 15 docentes de la educación básica. La metodología consistió en la transmisión de obras filmicas, en un total de ocho encuentros, con temática central sobre familias no convencionales. Durante la intervención aplicamos de forma individual un conjunto de instrumentos para colectas de datos, sin embargo, en este momento enfatizaremos los resultados obtenidos mediante aplicación del inventario con énfasis en el trabajo de Asociación Libre de Palabras (ALP), cuyo cual, fuera propuesto en el primero y en el último encuentro. Los datos obtenidos fueron categorizados con la ayuda del software EVOC y discutidos con base en la Teoría de las Representaciones Sociales (TRS), con apoyo de la Teoría del Núcleo Central (TNC). Concluimos que el cine asociado a otras estrategias que problematizen el concepto de familia posibilita movilizar y resignificar sentidos asociados a los conceptos de familia ideal y familia desestructurada.

Palabras clave: Formación docente. Cine. Representaciones sociales. Familias organizadas en modelos no convencionales. 


\section{A (RE)INVENÇÃO DA FAMÍLIA}

A família tradicional/nuclear - aquela que se sustenta na consanguinidade e no parentesco e se estrutura no binarismo de gênero (masculino-feminino), na qual cada um de seus membros tem um papel preestabelecido -, tida como "normal" e predominante até início do século XIX e meados do século XX, sofreu profundas alterações. E foi a partir da década de 1960 que nos deparamos com a família considerada contemporânea, pós-industrial ou pós-moderna - aquela que une dois indivíduos em prol de uma relação íntima e sexual e não mais em torno do cumprimento de papéis determinados socialmente. Esse período, objeto de nosso estudo, reflete as novas formas de parentesco, em que a transmissão da autoridade se torna problemática à medida que os arranjos conjugais são (re)configurados (ROUDINESCO, 2003; WAGNER, 2011).

Podemos elencar algumas mudanças que induziram essa reorganização familiar, uma vez que seria impossível apresentarmos todas diante da multiplicidade de possíveis vieses, são elas: as alterações demográficas, a maior longevidade humana, que deu um novo contexto à família - visto que hoje as pessoas estão vivendo com maior qualidade de vida, o que tem elevado o número de idosos -, a ressignificação da vida privada, a transmissão de bens, as mudanças nas relações Estado-família, nos papéis familiares, nos rituais de passagem, no lugar e no parentesco; e o ciclo vital da família. Estes são alguns dos inúmeros aspectos que incidiram na organização da família como ela se apresenta na contemporaneidade (HINTZ, 2001).

Outro fator está atrelado à mulher, que, culturalmente designada apenas aos afazeres domésticos, passa a trabalhar fora, tanto com a finalidade de aumentar a renda familiar quanto pelas oportunidades profissionais abertas pelo mercado de trabalho, o que teve como consequência, entre outras coisas, a afirmação do trabalho feminino, a princípio como necessidade e depois como valor. Aos poucos, as mulheres passam a ampliar seu campo de trabalho e a participar de atividades educativas, profissionais, culturais, artísticas e políticas (HINTZ, 2001; AMAZONAS, 2003; BARCELLOS, 2013).

Embora não possamos falar em total falência do patriarcado - uma forma de organização social e familiar que beneficia o homem em detrimento da mulher -, o seu declínio levou a transformações nos papéis parentais e nas relações de gênero, que passaram a influenciar grandemente as novas células familiares. Como consequência disso e das transformações sociais, culturais e econômicas, sobretudo no que diz respeito à ampliação do campo de trabalho feminino e de sua jornada, a mulher começa a passar mais tempo fora de casa. Deparamo-nos, a partir de então, com pais que 
dividem com as mulheres os cuidados e afetos aos filhos, exercendo uma função que era exclusivamente materna. A dinâmica das relações familiares passa a ser menos hierárquica, repercutindo uma menor verticalização entre pais e filhos.

Quanto à criança fruto das relações familiares atuais, "projetou-se uma identidade diferente da de seus pais. Com isso, a dominação paterna só pôde ser exercida numa partilha consentida que respeita o lugar de cada um dos parceiros ligados pela instituição matrimonial [...]" (ROUDINESCO, 2003, p. 101). Assim, os filhos adquirem maior liberdade de agir, e a figura paterna segue como a base desse sistema, porém com o mesmo grau de importância da figura materna, pois ambos são insubstituíveis (RIBEIRO; CRUZ, 2013; BARCELLOS, 2013).

O controle sobre a procriação a partir dos métodos anticonceptivos e conceptivos passa a ser uma realidade no planejamento familiar, pois as famílias podem evitar ter filhos ou mesmo contar com recursos da medicina reprodutiva, como barriga de aluguel, embriões congelados e reprodução artificial com doador de esperma anônimo, para escolher como e quando desejam conceber seus filhos. A democratização dessas técnicas " [...] possibilitou às mulheres diversificar suas experiências sexuais, desvinculando a sexualidade feminina dos avatares da procriação. As mulheres passaram a incluir a satisfação sexual entre os requisitos para a escolha do cônjuge [...]" (KEHL, 2003, p. 2).

Nesse sentido, o novo exercício dessa sexualidade e o olhar voltado à mulher e à criança na organização familiar ressignificou as relações de aliança. Ao dissociar o acesso ao prazer da função de procriação, a mulher reduziu paulatinamente o papel de esposa e de mãe.

No Brasil, mudança maior no conceito de família ocorreu com o advento da Constituição Federal da República, em 1988, que, impulsionada pelas expressivas modificações do contexto político, econômico e social do País, tratou de forma mais pontual da família, provocando uma verdadeira revolução em sua definição.

A família, base da sociedade, tem especial proteção do Estado.
[...] é reconhecida a união estável entre o homem e a mulher
como entidade familiar, devendo a lei facilitar sua conversão
em casamento. [...] Entende-se, também, como entidade fami-
liar a comunidade formada por qualquer dos pais e seus descen-
dentes (BRASIL, 1988, grifo nosso).

A ideia que se tinha sobre o casamento como o único "[...] instituto formador e legitimador da família brasileira, e do modelo de família hierarquizada, impessoal e, necessariamente, heterossexual, em que os interesses individuais cediam espaço à manutenção do vínculo [...]" é rompida a partir desse momento (PEREIRA, 2004, p. 
117). É válido ressaltarmos que ao mencionar a união estável formada entre um homem e uma mulher, a Constituição não reconheceu somente essa convivência como digna da proteção do Estado, mas a existência de uma mera recomendação em convertê-la em casamento, não negando a existência de famílias organizadas por pessoas do mesmo sexo.

O Supremo Tribunal Federal (STF) do Brasil em decisão histórica reconheceu, em 05 de maio de 2011, a união entre pessoas do mesmo sexo como entidade familiar, por unanimidade de votos, conferindo-lhe os mesmos efeitos jurídicos previstos para a União Estável. Assim, casais homossexuais passaram a ter o direito de casar, adotar filhos e registrá-los em seus nomes, deixar herança ao cônjuge, bem como incluí-lo como dependente nas declarações de imposto de renda e planos de saúde (LEÃO; SIMAS; FARIELLO, 2011). A partir de então, “Tribunais de todo o país estão seguindo o exemplo dos julgados favoráveis e agindo do mesmo modo, tendo por base os princípios da dignidade da pessoa humana e do respeito aos indivíduos [...]" (BARCELLOS, 2013, p. 45).

Nesse cenário de extrema mobilidade das configurações familiares, “[...] novas formas de convívio vêm sendo improvisadas em torno da necessidade - que não se alterou - de criar os filhos, frutos de uniões amorosas temporárias que nenhuma lei, de Deus ou dos homens [...]" (AMAZONAS, 2003, p. 1) consegue mais obrigar que se eternizem.

Assim, é possível afirmarmos que a composição do núcleo familiar, na atualidade, alicerça sua definição para além dos fatores biológicos e legais. "Aspectos da subjetividade que integram significados da convivência, por exemplo, têm sido um peso explicativo importante na definição da configuração familiar [...]" (WAGNER, 2011, p. 21). Dessa forma, a família da forma como ela se configura na contemporaneidade "[...] está baseada em relacionamentos e na qualidade das inter-relações, e não simplesmente em sua estrutura [...]” (POLLETO; KOLLER, 2008, p. 411).

A família não é mais singular, é plural, e essa multiplicidade não se refere simplesmente ao ato de nomear cada membro que a compõe, mas expressa as ideias que ultrapassam a consanguinidade próxima/distante, igual/desigual, que servem de evidência para um sistema inteiramente organizado e capaz de expressar centenas de diferentes relações de parentesco que permitem um indivíduo se organizar como família (ENGELS, 1984). Vemos nessas entidades familiares "[...] não somente um agregado mais vasto de pares biológicos, mas, sobretudo, um parentesco menos conforme aos laços naturais de consanguinidade [...]" (LACAN, 1981, p. 12) que a torna organizações extremamente complexas. Estamos diante de uma série de novos mo- 
delos de família, aquelas que nesse estudo nomeamos de famílias organizadas em modelos não convencionais.

Porém, mesmo diante dessas transformações, percebemos em nossa prática cotidiana que a escola nem sempre se mostra receptiva aos membros de famílias organizadas em modelos não convencionais, fato esse que, por inúmeras vezes, traduz-se como um fator de risco para o desenvolvimento saudável dos membros dessas famílias. Uma criança em idade escolar, por exemplo, pode perceber a escola como um ambiente hostil por ser oriunda de uma família organizada em modelos não convencionais e não ver o contexto escolar como acolhedor a sua organização familiar em datas comemorativas ou ritos escolares. No entanto, outra criança pode se sentir bem quando advinda de um modelo familiar tradicional/nuclear, pois é constantemente estimulada a participar das atividades oferecidas.

Diante desse cenário nos questionamos: quais famílias encontramos com maior frequência em nossas escolas? Seguimos de encontro ou ao encontro delas? Estamos lidando com sabedoria com as transformações da família contemporânea? Por que a escola ainda localiza na chamada "configuração familiar" um ponto nevrálgico ou uma possível solução para resolver os problemas de (in)disciplina na escola?

Muitas respostas a tais questionamentos evidenciam a ineficiência da implementação de estratégias educacionais que objetivam integrar a família ao contexto escolar, uma vez que tendem a afastar do seu interior as famílias organizadas por modelos não convencionais, que por elas são consideradas desestruturadas. Consequentemente, o processo de desenvolvimento e interação dos membros dessas instituições torna-se comprometido, em razão da sua dissociação.

Portanto, defendemos a necessidade de a escola (re)conhecer as variáveis que compõem as famílias, tal como elas se apresentam na contemporaneidade, uma vez que possibilitaria a efetivação de estratégias apropriadas de participação conjunta, bem como poderia fornecer orientações específicas, respeitando as particularidades dessa instituição, observando suas características culturais, os papéis e sua disponibilidade efetiva para concretizar atividades conjuntas dessas famílias com a escola.

\section{A EXPERIÊNCIA ESTÉTICA NA FORMAÇÃO DOCENTE}

A experiência estética é "[...] uma atitude desinteressada, é uma abertura, uma disponibilidade não tanto para a coisa ou o acontecimento 'em si', naquilo que ele tem de consistência, mas para os efeitos que ele pode produzir [...]" (PEREIRA, 2011, p. 111, grifo do autor), que não busca decifrar a essência da obra como se algo 
nela devesse ser revelado, mas se centra na capacidade de "[...] colocar em jogo uma relação experimental entre a significação dos objetos estéticos e a nossa experiência presente, ao permitir fazermos uma experiência com as experiências presentificadas pelos objetos [...]" (GUIMARÃES, 2004, p. 4).

Nesse sentido, o olhar estético propiciado por um filme, por exemplo, “[...] pode exercer certa capacidade de reflexão crítica [...]” (AUMONT, 2008, p. 22) e levar o sujeito "[...] a desenvolver uma compreensão pragmático-performativa do objeto que lhe é apresentado [...]" (GUIMARÃES, 2004, p. 3), capaz de transmitir ou, até mesmo, reelaborar o pensamento do espectador.

Por meio das histórias projetadas pelo cinema somos interpelados a assumir nosso lugar no cenário, para nos identificar com algumas (pre)posições e dispensar outras. Para Fabris (2005), nesse momento há uma simbiose entre as narrativas de vida dos personagens e dos espectadores que passam a ocupar o mesmo tempo e espaço representados na obra. "Quando assistimos a um filme, a experiência renova-se - é como se fosse a primeira vez, somos levados a um tempo inaugural, sempre no presente [...]" (FABRIS, 2005, p. 21). A experiência estética é análoga a uma viagem que nos possibilita visitar lugares, povos, culturas, línguas e costumes diferentes dos quais estamos acostumados a conviver. "Deslocamo-nos para o passado, presente e futuro na mesma velocidade das imagens que são apresentadas na tela [...]” (FABRIS, 2005, p. 21).

Nesse sentido, para viver a experiência estética, precisamos, antes de qualquer coisa, assumir uma atitude estética, ou seja, tomar uma posição que constitua e configure a nossa percepção, "não como uma intencionalidade, uma premeditação, uma antecipação racional do que está por vir, mas como uma disposição contingente, uma abertura circunstancial" à obra de arte e aos seus significados e significantes (PEREIRA, 2011, p. 114).

Essas implicações não correspondem à dissecação de um conteúdo - buscar com objetividade o que a arte quer dizer -, mas a propiciar diferentes modos de estar com nós mesmos e com o outro, é estimular o pensamento crítico, é transmitir um conteúdo quando a materialidade é portadora, "[...] quando ela veicula uma ideia, uma intenção, uma mensagem moral ou política; a arte pode representar algo quando, articulando sua potencialidade expressiva e comunicativa, significa algo, quando sua existência remete a algo que não está ali [...]” (PEREIRA, 2011, p. 112-113).

Pelas lentes do cinema é possível estabelecer uma representação concreta, dinâmica, sensitiva e emotiva do mundo, por meio de histórias que possibilitem ao espectador assimilá-la com mais naturalidade. A continuidade, o ritmo e a sequência lógica são recursos empregados para gerar a obra que possibilitam transportar o 
espectador a outra dimensão, pelo menos durante a projeção. A projeção fílmica é um convite a um voyeurismo que permite ao espectador transcender para um mundo paralelo, atribuindo valores ao que ele vê na tela, como um sujeito ativo no processo, portanto, “[...] sem o filme, com seu aparato técnico e o corpo de atores, não há espectador, da mesma forma em que não há filme sem um espectador que lhe confira significado [...]" (SILVA, 2012, p. 39).

A compreensão que os telespectadores fornecerão à transmissão das obras “[...] está ligada à capacidade de deleitar-se ou tocar pelas experiências, ou seja, tem a ver com a capacidade humana de maravilhar-se ou repugnar-se frente a um gesto, a uma paisagem, som ou ato [...]" (SOARES, 2008, p. 25). As sensações representadas pelo "concordo" ou "discordo" acabam sendo gradativamente substituídas por respostas mais emotivas geradas pela imagem - "gosto" ou "não gosto" -, o que corresponde a “[...] momentos em que o homem, exercitando suas capacidades sensíveis e inteligentes, se deixa tocar e frui entregando-se a uma experiência única [...]" (SOARES, 2008, p. 25) de aceitação ou rejeição visceral e de impacto, sem influência direta do racional.

Não queremos dizer com isso que o telespectador dispensa o raciocínio na (re)construção de conceitos, mas reafirmamos que, primeiramente, ele precisa passar pelas emoções, já que estas são a porta de entrada para posteriores construções sustentadas na lógica. "Quem está acostumado a se guiar pelo sentimento, pela emoção - provocada na maioria das vezes por imagens, externas ou internas - dificilmente aceitará raciocínios lógicos se a emoção não lhe facilitar o caminho [...]” (BLASCO et al., 2005, p. 123).

Portanto, ao pensarmos na relação entre família, formação docente e cinema como instâncias socializadoras que coexistem em uma relação de interdependência, precisamos envolver uma análise da relação dinâmica de tais instituições sociais que é estabelecida pelo conjunto de seus integrantes, seus recursos e nas trajetórias que esses sujeitos constroem na totalidade de suas ações e experiências, objetivas e subjetivas, uns com os outros.

Partindo desse pressuposto e diante do que já foi discutido até o momento, é necessário trazermos à baila outra pergunta recorrente quando se menciona a noção de família: o que, efetivamente, é compreendido como família pelo cinema? Tal indagação desafia novos questionamentos no século XXI, ocupando um lugar privilegiado no cenário problematizador do nosso cotidiano.

Em busca de respostas, partimos da premissa que o cinema é uma produção cultural que não apenas inventa histórias, mas que, na complexidade da produção de sentidos, vai criando, substituindo, limitando, incluindo e excluindo "realidades" 
(FABRIS, 2008, p. 120). "Essas imagens desenham e expressam valores que, consequentemente, implicam em conceitos ideológicos, sociológicos ou econômicos [...]" (SACRAMENTO, 2008, p. 8). A prevalência da família tradicional/nuclear, de grupamentos unidos por laços consanguíneos, afetivos ou eróticos ainda é uma constância em filmes que retratam cotidianos familiares. "De um modo ou de outro, entretanto, os tipos de convivências abordadas e as modalidades de rotinas exibidas quase sempre acabam se avizinhando do modelo estrutural de convivência familiar ou mesmo reproduzindo essa estrutura [...]” (FISCHER, 2009, p. 32).

O sucesso do cinema na construção desses modelos próximos do que é desejável socialmente "[...] remete à reflexão sobre o caráter retórico da produção fílmica, do efeito discursivo que o filme re/produz, colocando em questão a dimensão do que se concebe como 'realidade' [...]" (SILVA, 2012, p. 38, grifo do autor). Nesse aspecto, a chamada "sétima arte" pode ser considerada "[...] como uma instância cultural repleta de (re)significados e sentidos, e que os seus conteúdos e formas, desde que tratados de modo interpretativo e crítico, adquirem uma dimensão estética muito significativa na formação de conceitos e valores [...]” (FRAGA, 2012, p. 18).

Ao questionarmos esses preceitos pensamos no cinema como uma ferramenta de formação docente ao evidenciar modelos alternativos de famílias, para além do ideário da família tradicional/nuclear, que apresentem bom funcionamento, que criem "[...] sentidos que a alimentam, ampliando, suprimindo e/ou transformando significados [...]" (FABRIS, 2008, p. 120) ao propor a identificação dos arranjos particulares e as vivências específicas de sujeitos singulares, evidenciando os processos-chave que possibilitam às famílias organizadas em modelos não convencionais, não somente lidarem mais eficientemente com situações de crise ou estresse permanente, mas saírem fortalecidas delas, processo esse que Walsh (2005) denomina resiliência familiar.

\section{PERCURSO METODOLÓGICO}

Apresentamos neste estudo um recorte de um trabalho de doutoramento assumindo o objetivo de problematizar o conceito de "família ideal" e "família desestruturada" em professores da educação básica da rede pública de ensino. Os dados que subsidiaram essa proposta foram coletados no curso de formação docente intitulado: Formação de professores e experiência estética: representações de resiliência em famílias não convencionais pelas lentes do cinema, ofertado em 2016 na Universidade Estadual do Paraná, após a aprovação do Comitê de Ética para Pesquisa com Seres Humanos. 
Esta pesquisa envolveu alunas do Curso de Pedagogia que foram convidadas a participar do processo de formação, desde que atendessem aos seguintes requisitos: exercer o magistério na educação básica, ter disponibilidade de participação aos sábados, interesse e comprometimento em participar de todo o processo e ler e assinar o Termo de Consentimento Livre e Esclarecido (TCLE).

Após a seleção participaram dos encontros de formação 15 professoras, cuja média de idade era de 23 anos. Elas exerciam o magistério há aproximadamente dois anos e meio; 11 declararam como estado civil solteiras, duas, casadas e duas, divorciadas; oito atuavam na educação infantil em período integral e sete nos anos iniciais do ensino fundamental; e oito eram acadêmicas do terceiro ano do Curso de Pedagogia e sete do primeiro ano.

Foram coletadas e analisadas as associações livres de palavras (ALP) das educadoras sobre o conceito de "família ideal" e "família desestruturada", mediante a aplicação de um instrumento de evocação livre de palavras - por meio do qual as respondentes eram estimuladas a associar até cinco palavras, sentimentos ou imagens a cada uma dessas expressões indutoras, sempre no formato de palavras e expressões e não frases ou textos. A aplicação do instrumento ocorreu de forma individual no primeiro encontro, o qual denominamos de momento pré-interventivo, e no oitavo encontro, caracterizado como momento pós-interventivo, por ser o último momento da formação docente.

O método de ALP, além de combinar a frequência da emissão de palavras, sentimentos ou imagens com a ordem com que são evocadas, possibilita criar um conjunto de categorias, organizadas ao redor desses elementos, possibilitando a projeção das indicações sobre o papel organizador das representações a fim de demonstrar os núcleos de resistência dos sujeitos quanto ao assunto investigado (ABRIC, 1998, 2003; MOSCOVICI, 1978, 2015).

As palavras evocadas foram categorizadas com o auxílio do software EVOC e seus subprogramas TRIEVOC, RANGMOT, NETTOIE e RANGFRQ e discutidas à luz da Teoria das Representações Sociais (TRS), formulada por Moscovici (1978, 2015) e introduzida na França, em 1961, por meio da obra La Psychanalyse: son image et son public, editada no Brasil, em 1978, com o título A Representação Social da Psicanálise. Como complemento à TRS, empregamos a perspectiva de Abric (1998), que formulou a Teoria do Núcleo Central (TNC), a qual visa compreender o conteúdo cognitivo das possíveis representações.

Para Moscovici (2015, p. 53, grifo do autor) “[...] as representações sociais devem ser vistas como uma 'atmosfera', em relação ao indivíduo ou ao grupo; as re- 
presentações são, sob certos aspectos, específicas de nossa sociedade [...]" Esse conhecimento, ao ser compartilhado, acaba por direcionar posturas e condutas que justificam tomadas de posições e a construção de certas identidades, dando resguardo às particularidades de determinados extratos sociais. "A visão de sujeito para essa teoria é contextualizada social e historicamente, pois, ao mesmo tempo em que o sujeito constrói a realidade social, nela é construído de forma ativa [...]" (RIBEIRO; CRUZ, 2013, p. 615).

Ao buscarmos respaldo na TRS, assumimos o pressuposto de que as representações sociais sobre "família ideal" e "família desestruturada" procuram ilustrar a maneira como um conjunto de conceitos, proposições e explicações históricas, míticas ou de crenças, estabelecidos nas associações originadas no cotidiano de um grupo de professoras, torna-se senso comum e passa a compor seu repertório, favorecendo o estabelecimento de parentescos analógicos de uns para com os outros.

O registro das reações e falas dos participantes, durante e após a projeção dos filmes, foi feito mediante observação e relatos em páginas de redes sociais, criadas especificamente para o Curso de formação - Facebook e WhatsApp. Os dados obtidos compuseram o diário de campo com o intuito de recolher, registrar e analisar as falas, opiniões e expressões nos distintos momentos da intervenção, das quais o grupo investigado pode ou não ter consciência, mas que sustentam o seu discurso.

O debate dessas informações foi pautado na análise de conteúdo proposta por Bardin (2010), com a intenção de avaliar o discurso de quem fala e de onde fala por meio da captação de falas espontâneas das participantes, como uma representação livre daquilo que elas vivenciam, sentem e pensam sobre "família ideal” e "família desestruturada" (BARDIN, 2010).

A análise de conteúdo permite ao analista compreender como o conteúdo produz sentido na formação da subjetividade do discurso do sujeito eloquente, uma vez que nesse tipo de pesquisa a subjetividade é uma constante, pois quando

[...] Diz "Eu", com o seu próprio sistema de pensamentos, os
seus processos cognitivos, os seus sistemas de valores e de re-
presentações, as suas emoções, a sua afetividade e a afloração
do seu inconsciente. E ao dizer "Eu", mesmo que esteja a falar
de outra pessoa ou de outra coisa, explora, por vezes às apal-
padelas, uma certa realidade que se insinua através do "estrei-
to desfiladeiro da linguagem", da sua linguagem, porque cada
pessoa serve-se dos seus próprios meios de expressão para des-
crever acontecimentos, práticas, crenças, episódios passados,
juízos [...] (BARDIN, 2010, p. 89-90, grifo do autor).

Nesse sentido, os resultados obtidos mediante a ALP e o diário de campo foram empregados como instrumentos complementares para a coleta de dados. 
O processo interventivo consistiu na transmissão de oito obras cinematográficas em dias distintos, com os seguintes títulos:

a) Baby Love (Comme les autres): um filme que retrata a busca pela parternidade de um casal homossexual masculino (BABY..., 2008);

b) Bella: narra a história de uma moça solteira que descobre que está grávida e recebe a ajuda de um ex-colega de trabalho que abandona tudo para acompanhá-la em uma jornada de autoconhecimento (BELLA, 2006);

c) De coração partido (Like dandelion dust): um drama sobre um garoto que vive uma vida idílica com seus pais adotivos na costa da Flórida). Tudo corria bem até o dia que eles recebem um telefonema perturbador: os pais biológicos do menino o querem de volta (DE CORAÇÃO..., 2009);

d) Os garotos estão de volta (The boys are back): tem como narrativa a história de um jornalista esportivo que, após a trágica morte de sua segunda esposa, precisa tomar conta de seu filho, um garoto de seis anos, e do filho de seu casamento anterior, de 14 anos, que se muda para viver com ele durante uma temporada (OS GAROTOS..., 2009);

e) Pelos olhos de Maisie (What Maisie knew): um filme sobre um conturbado divórcio de um casal, no qual uma garotinha de sete anos tenta entender o que está acontecendo. A menina logo descobre um novo significado para a palavra família (PELOS..., 2012);

f) Um dia desses (Any day now): retrata uma história situada nos anos 1970, em que um casal gay adota um jovem com Síndrome de Down abandonado pela mãe biológica viciada em drogas. A criança encontra em seus novos pais a família que nunca teve (UM DIA..., 2012);

g) Uma lição de amor (I am Sam): um homem com deficiência mental cria sua filha com a ajuda de seus amigos. Porém, aos sete anos de idade, a menina começa a ultrapassar intelectualmente seu pai, e esta situação chama a atenção de uma assistente social que tenta destituir o poder patriarcal. A partir de então, o pai enfrenta uma batalha judicial para manter a custódia da filha (UMA LIÇÃO..., 2002);

h) A razão do meu afeto (The object of my affection): uma assistente social conhece um rapaz gay que acaba indo morar na casa dela e dividindo as despesas. Ela tem um namorado que, apesar de tudo, aceita a situação. Ao descobrir que está grávida do namorado ela quer a pre- 
sença do amigo, com o qual tem passado cada vez mais tempo junto e por quem está apaixonada (A RAZÃO..., 1998).

Esses filmes foram escolhidos dentro de um universo de 38 obras fílmicas, selecionadas previamente por indicação ou pesquisas na rede mundial de computadores, pois atendiam aos seguintes critérios para a inclusão no projeto: o tema central da narrativa tratava sobre famílias organizadas em modelos não convencionais, não ultrapassavam o período de exibição de 140 minutos e as famílias retratadas nos filmes apresentavam os três processos-chave de resiliência familiar apontados por Walsh (2005): sistemas de crença, padrões organizacionais e processos de comunicação. Portanto, era necessário que as famílias retratadas nos filmes, independentemente da forma como se organizavam, fossem capazes de resistir e se sobressair às intempéries da vida contando com o apoio uns dos outros.

Após as projeções fílmicas, foram realizadas problematizações das obras com perguntas que levavam as professoras a expressarem seus sentimentos e emoções em relação aos personagens, ao papel da escola no acolhimento da família retratada no filme e à capacidade de aquela organização familiar funcionar bem. Posteriormente, eram propostas situações problemas do cotidiano escolar, envolvendo as famílias dos filmes, a serem resolvidas em grupo. Os resultados dessa etapa constituíram parte do corpus do diário de campo e subsidiaram as discussões apresentadas a seguir.

Para além dos autores já citados, os quais constituíram parte do nosso referencial teórico, chamamos a atenção de nossos leitores ao fato de que os dados obtidos nos levaram a aprofundar nossas investigações em autores que discutem a relação entre família e escola, como: Yunes, Garcia e Albuquerque (2007), Andrade (2002), e Ribeiro e Cruz (2013), os quais investigam as representações sociais no processo de formação tanto do educador quanto da criança; Poletto e Koller (2008) e Silva et al. (2009), os quais têm como sustentáculo de suas pesquisas os contextos ecológicos, entre eles, a família e a escola, como sistemas que podem promover a resiliência, os fatores de risco e de proteção de seus membros; e Pereira (2004) e Wagner (2011), que preconizam os princípios fundamentais e norteadores para a organização jurídica da família, bem como seus desafios na contemporaneidade.

\section{RESULTADOS E DISCUSSÕES}

Mediante o emprego da frase indutora: quais sentimentos, imagens ou palavras vêm a sua mente quando pensa em família desestruturada, obtivemos um pa- 
norama de 68 ALP no momento pré-teste, ranqueadas pelos subprogramas TRIEVOC e RANGMOT. Dessa coletânea, 34 apresentaram significados diversos. As palavras com a mesma conotação foram corrigidas, filtradas e categorizadas com o auxílio do subprograma NETTOIE.

Por meio do subprograma RANGFRQ, organizamos nossos dados em quadrantes, nos quais se encontram os elementos estruturais das evocações, agrupados a partir de dois critérios básicos: frequência e Ordem Média de Evocação (OME). Para Abric (1998), a centralidade de um elemento, embora deva ser atribuída a critérios quantitativos e qualitativos, define-se mais pela dimensão qualitativa que o elemento oferece à representação do que pela sua presença expressiva, do ponto de vista quantitativo. Nessa direção, Sá $\left(1996^{a}\right.$, 1996b) apresenta as quatro propriedades relativas às cognições centrais: valor simbólico, poder associativo, saliência e forte conexidade na estrutura. As duas primeiras são qualitativas, ditadas pela teoria das representações sociais; as duas últimas são quantitativas e decorrem das anteriores.

Nesse sentido, nossos dados serão apresentados em "quatro casas", de maneira a apontar a frequência das evocações em forma de quatro quadrantes, enfatizando as palavras que compõem o núcleo central das evocações (palavras induzidas com maior frequência) no primeiro quadrante à esquerda, os elementos intermediários no primeiro quadrante à direita e os periféricos (palavras que figuraram com menor frequência) nos quadrantes abaixo. Assim, podemos observar que os dois quadrantes superiores apresentam as palavras induzidas com maior frequência e os inferiores, aquelas que figuraram com menor frequência.

Sobre o núcleo central, ancorados em Sá (1996a, 1996b), podemos atribuir algumas características essenciais que auxiliam na sua definição e compreensão. Ele é caracterizado pela memória coletiva, refletindo as condições históricas, sociais e valorativas de determinado grupo; constitui o consenso das representações, a base comum partilhada coletivamente que acaba por homogeneizar aquele grupo social; tem como principal característica a estabilidade, a coerência e a resistência a mudanças, dando seguridade, continuidade e permanência da representação; possui pouca sensibilidade ao contexto social e material imediato em que a representação se manifesta; e tem como função primordial gerar o significado básico da representação, possibilitando a organização global de todos os elementos que a constituem.

Já o sistema periférico, por sua vez, apresenta características diferentes do núcleo central, em razão de que possibilita a integração das vivências individuais, convive com a heterogeneidade e as possíveis contradições do grupo e é evolutivo e pode ser afetado pelo contexto imediato. Em síntese, “[...] suas funções consistem, 
em termos atuais e cotidianos, na adaptação à realidade concreta e na diferenciação do conteúdo da representação e, em ternos históricos, na proteção do sistema central [...]" (SÁ, 1996b, p. 22).

Assim, quando as pessoas emitem julgamentos aparentemente absolutos, como, por exemplo, sobre os conceitos, objetos de nosso estudo, já se encontram nesses valores incutidas distintas alternativas condicionais tidas como legítimas ou mesmo condicionalmente genéricas ou abertas. É essa hipótese da condicionalidade que propicia um critério analítico para distinguir entre as cognições do núcleo central, consideradas absolutas, e as cognições periféricas, tidas como condicionais, ao mesmo tempo em que permite conferir maior plausibilidade à dinâmica relacional entre os elementos cognitivos dos dois sistemas.

Ao empregarmos os preceitos dessa teoria, buscamos (re)conhecer os mecanismos cognitivos ou afetivos do grupo de docentes investigado - enquanto indicadores de processos subjetivos que compõem o núcleo central e os elementos periféricos das representações acerca de "família desestruturada" e "família ideal" -, bem como representar os mais distintos mecanismos de defesa que o sujeito manifesta, mesmo que de maneira inconsistente, a fim de manter seus conflitos dentro de uma margem tolerável, como, por exemplo:

[...] das disjunções de pessoa, tempo ou lugar (pelos quais o entrevistado, referindo-se a outra(s) pessoa(s), outro tempo, ou lugar, considera implicitamente a si mesmo e às circunstâncias que o envolvem); do discurso ideológico (o recurso à repetição de ideias que servem para disfarçar as contradições e os conflitos presentes no discurso); ou ainda dos recursos próprios às funções conativa e fática (funções da linguagem pelas quais o entrevistado busca, sem que necessariamente o perceba, apoio ou atenção do entrevistador para seu discurso). (ANDRADE, 2002, p. 29-30).

Nesse sentido, por meio do Quadro 1 é possível compreender como se organizaram as representações, constituídas no senso coletivo das participantes desta pesquisa, no pré-teste, diante da expressão indutora "família desestruturada", em que o vocábulo mais citado no quadrante superior esquerdo foi briga (10), o que representa o possível núcleo central das representações.

$\mathrm{Na} 1^{\mathrm{a}}$ periferia (quadrante superior direito), as evocações abandono (4), desunião (4), tristeza (5) e violência (4) compõem o núcleo intermediário das representações acerca de "família desestruturada". 
Por sua vez, as palavras, sentimentos ou imagens, como desentendimento (2), desrespeito (2), falta de amor (3), filho desamparado (2), individualismo (2) e infelicidade (2) representam os elementos intermediários da $2^{\mathrm{a}}$ periferia.

A carência (2), o complexo (2), a frustração (2) e a insegurança (2), mesmo apresentando valores semelhantes aos elementos da periferia anterior, compõem os elementos intermediários da $3^{\mathrm{a}}$ periferia por terem sido evocados menos prontamente, ou seja, não eram uma evocação feita imediatamente após o estímulo.

Quadro 1 - Expressões sobre "família desestruturada" no pré-teste - RANGFRQ²

\begin{tabular}{|c|c|c|c|c|c|}
\hline \multicolumn{3}{|c|}{ NÚCLEO CENTRAL } & \multicolumn{3}{|c|}{$\begin{array}{l}\text { ELEMENTOS INTERMEDIÁRIOS/1 }{ }^{\mathrm{a}} \\
\text { Periferia }\end{array}$} \\
\hline \multicolumn{3}{|c|}{$\begin{array}{l}\text { Cas ou la Fréquence }>=4 \text { et le Rang Moyen } \\
<2,6\end{array}$} & \multicolumn{3}{|c|}{$\begin{array}{l}\text { Cas ou la Fréquence }>=4 \text { et le Rang Moyen } \\
>=2,6\end{array}$} \\
\hline \multirow[t]{4}{*}{ Briga } & 10 & 2,500 & Abandono & 4 & 2,750 \\
\hline & & & Desunião & 4 & 3,750 \\
\hline & & & Tristeza & 5 & 3,200 \\
\hline & & & Violência & 4 & 3,500 \\
\hline \multicolumn{3}{|c|}{$\begin{array}{l}\text { ELEMENTOS INTERMEDIÁRIOS/2a } \\
\text { Periferia }\end{array}$} & \multicolumn{3}{|c|}{$\begin{array}{l}\text { ELEMENTOS INTERMEDIÁRIOS/ } 3^{\mathrm{a}} \\
\text { Periferia }\end{array}$} \\
\hline \multicolumn{3}{|c|}{$\begin{array}{l}\text { Cas ou la Fréquence }<4 \text { et le Rang Moyen } \\
<2,6\end{array}$} & \multicolumn{3}{|c|}{$\begin{array}{l}\text { Cas ou la Fréquence }<4 \text { et le Rang Moyen } \\
>=2,6\end{array}$} \\
\hline Desentendimento & 2 & 2,000 & Carência & 2 & 3,500 \\
\hline Desrespeito & 2 & 2,000 & Complexo & 2 & 3,500 \\
\hline Falta de amor & 3 & 1,000 & Frustração & 2 & 4,500 \\
\hline Filho desamparado & 2 & 1,000 & Insegurança & 2 & 3,000 \\
\hline Individualismo & 2 & 1,500 & & & \\
\hline Infelicidade & 2 & 2,500 & & & \\
\hline
\end{tabular}

Fonte: o autor.

Diante da palavra disparadora "família desestruturada", no momento pós-teste, o TRIEVOC aponta para um quantitativo de 74 palavras evocadas, das quais

\footnotetext{
${ }^{2}$ Embora haja um procedimento matemático com base no cálculo logaritmo das frequências para se escolher os valores de frequência mínima e intermediária a serem preenchidos no RANGFRQ, isso costuma ser feito pela observação das distribuições das palavras na lista de frequência. Escolhe-se, por exemplo, como valor da frequência intermediária uma frequência tal que, a partir dela, o número de palavras que aparecem com alta frequência é homogêneo e pequeno. Por exemplo, no Quadro 1, a frequência intermediária escolhida foi de 4 porque o número de palavras a partir dessa frequência se tornou homogêneo e com valores pequenos. Em termos qualitativos, isso significa que a partir da frequência intermediaria há poucas palavras que aparecem muitas vezes e que sinalizarão, provavelmente, os elementos centrais das representações. A frequência mínima a ser marcada no RANGFRQ deve corresponder a um valor de frequência que marque que antes dele muitas palavras se repetiram poucas vezes, o que mostra que são pouco significantes para revelar representações sociais. No Quadro 1, a frequência mínima escolhida foi 2,6, sendo que as palavras com frequência menor que esta não foram consideradas no programa RANGFRQ (MENIN; ZECHI, 2003).
} 
33 possuem significados diferentes de acordo com o RANGMOT. Com o auxílio do NETTOIE, agrupamos as palavras que apresentavam o mesmo significado ou radical semelhante.

Com o auxílio do subprograma RANGFRQ, no Quadro 2 apresentamos as evocações separadas em quadrantes, realizadas após o programa de formação ao empregar a expressão "família desestruturada". No primeiro quadrante superior estão as palavras tidas como núcleo central das representações, por terem figurado com maior frequência e prontidão. A palavra briga (9), assim como no pré-teste, foi a palavra mais prontamente representada como característica desse tipo de família, ou seja, mostrou-se resistente a mudanças e ao processo de intervenção, pois tem como função organizar os demais elementos que constituem as representações. Porém, nesse momento da pesquisa, foram incorporados novos sentimentos, como desafeto (4) e falta de amor (7), ocupando a primeira, a segunda e a terceira ordem de evocações.

No núcleo intermediário da $1^{\mathrm{a}}$ periferia, da mesma maneira que no préteste, a palavra abandono (5) manteve-se entre as mais evocadas de primeira ordem, porém, no pós-teste, o fator irresponsabilidade (7) foi acrescido entre as palavras, sentimentos ou imagens de quarta e quinta ordem. Hipoteticamente, a incorporação desse sentimento se deve à experiência estética que o cinema propiciou, principalmente em títulos como Bella e Pelos olhos de Maisie, pois observamos, por meio dos registros no diário de campo, que as professoras, durante a transmissão fílmica desses títulos, atribuíram a irresponsabilidade como um aspecto negativo para o funcionamento das organizações familiares.

Uma das professoras conclui fazendo alusão às histórias de vida de seus alunos que vivenciam o abandono e a irresponsabilidade dos pais e das mães em situações similares.

Os quadrantes intermediários, de $2^{\mathrm{a}}$ e $3^{\mathrm{a}}$ periferia, evidenciam as evocações que figuraram em menor número e menor prontidão. Entre elas estão: descompromisso (2), desrespeito (2), falta de condições (2), infelicidade (2) e, na sequência, agressão (2), desatenção (2), desunião (3), individualismo (2), mágoa (3), transtorno emocional (2) e tristeza (3). 
Quadro 2 - Expressões sobre "família desestruturada" no pós-teste - RANGFRQ

\begin{tabular}{|c|c|c|c|c|c|}
\hline \multicolumn{3}{|c|}{ NÚCLEO CENTRAL } & \multicolumn{3}{|c|}{$\begin{array}{l}\text { ELEMENTOS INTERMEDIÁRIOS/1a } \\
\text { Periferia }\end{array}$} \\
\hline \multicolumn{3}{|c|}{$\begin{array}{l}\text { Cas ou la Fréquence }>=4 \text { et le Rang Moyen } \\
<2,6\end{array}$} & \multicolumn{3}{|c|}{$\begin{array}{l}\text { Cas ou la Fréquence }>=4 \text { et le Rang Moyen } \\
>=2,6\end{array}$} \\
\hline Briga & 9 & 1,889 & Abandono & 5 & 3,200 \\
\hline Desafeto & 4 & 2,250 & Irresponsabilidade & 7 & 3,714 \\
\hline Falta de amor & 7 & 2,143 & & & \\
\hline \multicolumn{3}{|c|}{$\begin{array}{l}\text { ELEMENTOS INTERMEDIÁRIOS/2a } \\
\text { Periferia }\end{array}$} & \multicolumn{3}{|c|}{$\begin{array}{l}\text { ELEMENTOS INTERMEDIÁRIOS/3a } \\
\text { Periferia }\end{array}$} \\
\hline \multicolumn{3}{|c|}{$\begin{array}{l}\text { Cas ou la Fréquence }<4 \text { et le Rang Moyen } \\
<2,6\end{array}$} & \multicolumn{3}{|c|}{$\begin{array}{l}\text { Cas ou la Fréquence }<4 \text { et le Rang Moyen } \\
>=2,6\end{array}$} \\
\hline Descompromisso & 2 & 2,500 & Agressão & 2 & 3,500 \\
\hline Desrespeito & 2 & 2,500 & Desatenção & 2 & 4,500 \\
\hline Falta de condições & 2 & 1,500 & Desunião & 3 & 3,333 \\
\hline \multirow[t]{4}{*}{ Infelicidade } & 2 & 2,000 & Individualismo & 2 & 3,000 \\
\hline & & & Mágoa & 3 & 2,667 \\
\hline & & & $\begin{array}{l}\text { Transtorno emo- } \\
\text { cional }\end{array}$ & 2 & 3,500 \\
\hline & & & Tristeza & 3 & 4,667 \\
\hline
\end{tabular}

Fonte: o autor.

Após o programa de formação de professores e experiência estética, percebemos que as brigas continuaram a figurar o imaginário coletivo das participantes da intervenção quando pensavam em "famílias desestruturadas”, porém, nesse momento, sentimentos como falta de amor e desafeto foram acrescidos à categoria central das representações sociais.

O uso do termo indutor "família desestruturada" como estímulo foi propositalmente pensado pelo fato de acreditarmos que determinadas professoras culpabilizam as famílias organizadas em modelos não convencionais pelo fracasso escolar de seus filhos, em razão da nossa experiência em gestão escolar e pela observação de apontamentos por elas realizados em reuniões pedagógicas e encontros de professores. Yunes, Garcia e Albuquerque (2007, p. 445, grifo nosso) apontaram em seu estudo que, parte considerável dos educadores “[...] caracterizavam as famílias como 'desestruturadas', pela sua configuração não nuclear [...]”'

No entanto, os dados evidenciados nessa etapa da pesquisa desmistificaram nossa hipótese de que as professoras pudessem fazer associações a palavras como divórcio, pais homossexuais, padrasto, madrasta, crianças adotivas, adoção, crianças criadas pelos avós, etc., em virtude de que isso não ocorreu. 
Para as professoras, as brigas constantes, associadas ao abandono que os membros familiares sofrem daqueles que os deveriam proteger, a falta de união entre os entes e a tristeza que esses fatores propiciam são aspectos que desestruturam as famílias, impedindo seu bom funcionamento. Tais fatores acabam por gerar diversas formas de "[...] violência nas relações intrafamiliares apontadas, como abandono, negligência das crianças e incidência do uso de drogas por pelo menos um membro da família [...]" (YUNES; GARCIA; ALBUQUERQUE, 2007, p. 445).

$\mathrm{Na}$ visão das participantes, qualquer que seja a forma de violência gerada no bojo familiar culmina em desentendimentos, que promovem a falta de respeito de uns para com os outros, estafam o sentimento de amor entre os entes familiares, diluem o coletivo imperando a individualidade e, consequentemente, os filhos dessas relações se tornam desamparados, gerando infelicidade durante e após o período de interação com os fatores de risco.

Nesse sentido, as participantes apontaram que, independentemente da organização familiar, o que desestrutura uma família é o seu nível de funcionamento e não a sua formatação, como apontam alguns discursos registrados no diário de campo (informações verbais):

Não importa como seja os constituintes dessa instituição, se são parecidos ou diferentes, o importante é o respeito, amor e a estrutura que ela proporciona ao indivíduo [...]

[...] independente da configuração social da família o que deve ser colocado em evidência é a estrutura emocional.

[...] independentemente do tipo de família, o amor e atenção devem estar sempre presentes.

Independentemente do tipo de família e como ela se constitui, é o amor e a amizade do lar que fazem com que nos tornemos pessoas realizadas.

Não podemos dizer que há um único tipo de família. Na verdade, há variadas estruturas e formas de se organizá-la [...] não importa como é formada e sim como ela funciona [...] é questão de afetividade, consideração, apoio e respeito.

[...] o fator que define uma família não deveria estar baseado em sua estrutura, mas, sim, no carinho e nas demonstrações de amor $[\ldots]$

[...] a família é a nossa identidade, e só se chama família quando há amor e respeito, e para isso não importa se é tradicional, ou se é mãe solteira, ou se os pais são adotivos [...] 
Nos elementos intermediários, percebemos um deslocamento de palavras, sentimentos ou imagens do pré para o pós-teste, de uma periferia para a outra. Isso nos permite apontar que as participantes mantiveram o discurso de que os aspectos desestabilizantes das famílias disfuncionais estão estreitamente relacionados ao desempenho dos papéis de seus integrantes que, quando distorcidos, geram inadequações e mau funcionamento, o que independe da configuração familiar.

Poletto e Koller (2008, p. 411) corroboram essa visão ao afirmarem que, para além da configuração familiar, as famílias “[...] que apresentam coesão, aconchego, continência e estabilidade, nas quais as relações são permeadas por afeto, equilíbrio de poder, cuidados adequados, senso de pertencimento e disciplina consistente, são mais propensas a ter membros saudáveis emocionalmente [...]", pois tais aspectos possibilitam que as pessoas ou as famílias "[...] administrem as adversidades que enfrentam, de forma a encontrar respostas aos seus problemas e suas necessidades [...]" (SILVA et al., 2009, p. 93).

No que se refere às evocações de "família ideal" obtivemos no pré-teste, com o auxílio dos softwares TRIEVOC e RANGMOT, um panorama de 64 evocações, sendo que 27 palavras, sentimentos ou imagens possuíam conotação diferente.

A palavra união teve maior representatividade, tanto em quantidade quanto em colocação das ALP, figurando na primeira ordem. O sentimento amor aparece com a mesma frequência, porém elencado em ordem díspar. O ponto crucial das representações acerca de "família ideal” está apresentado no Quadro 3, que novamente organiza as palavras evocadas em quatro quadrantes.

O Quadro 3 demonstra que as palavras mais citadas foram amor (8), diálogo (4) e união (8), porém é possível perceber que a palavra diálogo, que se encontra no primeiro quadrante, aparece menos vezes do que as do segundo quadrante. Isso quer dizer que essas palavras foram evocadas com maior frequência entre o primeiro ou segundo lugar, passando, assim, a compor parte do núcleo central das representações sobre "família ideal".

Sá (1996a, 1996b) aponta em seus estudos que devemos conceder igual ênfase aos elementos periféricos, bem como destacar sua complementaridade funcional e, principalmente, estabelecer comparações e relações entre as representações e as práticas sociais. Nesse sentido, não menos essencial que o núcleo central, na teoria das representações sociais, o núcleo intermediário de $1^{\text {a }}$ periferia vem complementar as evocações docentes de "família ideal", trazendo as evocações de palavras, imagens ou sentimentos, como companheirismo (4), paciência (4) e respeito (6) entre os elementos de terceira, quarta e quinta ordens. 
Os quadrantes de $2^{\mathrm{a}}$ e $3^{\mathrm{a}}$ periferia evidenciam as representações que figuraram em menor frequência e menor prontidão, entre elas estão, respectivamente, felicidade (2) no terceiro quadrante, e afeto (2), carinho (2), compreensão (3), filho (2), flexibilidade (2) e proteção (3), no quarto quadrante.

Percebemos, assim, que o amor, o diálogo e a união foram os valores com maior representatividade no momento investigativo do pré-teste pelas educadoras que participaram da coleta de dados ao fazerem associações com a expressão indutora "família ideal".

Quadro 3 - Expressões sobre "família ideal" no pré-teste - RANGFRQ

\begin{tabular}{|c|c|c|c|c|c|}
\hline \multicolumn{3}{|c|}{ NÚCLEO CENTRAL } & \multicolumn{3}{|c|}{$\begin{array}{l}\text { ELEMENTOS INTERMEDIÁRIOS/1a } \\
\text { Periferia }\end{array}$} \\
\hline \multicolumn{3}{|c|}{$\begin{array}{l}\text { Cas ou la Fréquence }>=4 \text { et le Rang Moyen } \\
<2,6\end{array}$} & \multicolumn{3}{|c|}{$\begin{array}{l}\text { Cas ou la Fréquence }>=4 \text { et le Rang Moyen } \\
>=2,6\end{array}$} \\
\hline Amor & 8 & 2,500 & Companheirismo & 4 & 3,500 \\
\hline Diálogo & 4 & 2,250 & Paciência & 4 & 3,500 \\
\hline União & 8 & 2,250 & Respeito & 6 & 3,000 \\
\hline \multicolumn{3}{|c|}{$\begin{array}{l}\text { ELEMENTOS INTERMEDIÁRIOS/2a } \\
\text { Periferia }\end{array}$} & \multicolumn{3}{|c|}{$\begin{array}{l}\text { ELEMENTOS INTERMEDIÁRIOS } / 3^{\mathrm{a}} \\
\text { Periferia }\end{array}$} \\
\hline \multicolumn{3}{|c|}{$\begin{array}{l}\text { Cas ou la Fréquence }<4 \text { et le Rang Moyen } \\
<2,6\end{array}$} & \multicolumn{3}{|c|}{$\begin{array}{l}\text { Cas ou la Fréquence }<4 \text { et le Rang Moyen } \\
>=2,6\end{array}$} \\
\hline \multirow[t]{6}{*}{ Felicidade } & 2 & 2,500 & Afeto & 2 & 3,000 \\
\hline & & & Carinho & 2 & 3,500 \\
\hline & & & Compreensão & 3 & 3,667 \\
\hline & & & Filho & 2 & 3,500 \\
\hline & & & Flexibilidade & 2 & 3,500 \\
\hline & & & Proteção & 3 & 2,667 \\
\hline
\end{tabular}

Fonte: o autor.

Na segunda aplicação do teste, pós-intervenção, diante da expressão estímulo "família ideal", foram evocadas 75 palavras, sentimentos ou imagens, sendo que o software RANGMOT elencou 33 evocações distintas. O subprograma nos apontou para uma listagem em que o sentimento amor faz parte do imaginário coletivo da maioria das professoras que participaram da intervenção, sendo representado 13 vezes, com maior figuração na primeira ordem de citação, isto é, para essas docentes, o amor é o principal sentimento que lhes vem à mente quando o tema é "família ideal". $\mathrm{O}$ respeito também foi representado por mais da metade das respondentes, oito ao todo, porém foram evocadas em terceira ordem. 
A Teoria do Núcleo Central nos auxilia na compreensão do Quadro 4, que sintetiza as palavras que foram evocadas duas ou mais vezes. Dessa forma, no primeiro quadrante figuram as palavras que foram evocadas com maior frequência e prontidão, entre elas o amor (13) e a união (4), compondo o núcleo central das representações.

No segundo quadrante, do lado direito, estão as palavras que se relacionam ao núcleo central, como afeto (6), cuidado (4), felicidade (4) e respeito (8). Embora os elementos intermediários da $1^{\mathrm{a}}$ periferia, algumas vezes, figurem em números maiores do que as representações do núcleo central, eles não foram absorvidos no primeiro quadrante em razão da ordem com que foram evocados pelas participantes, figurando em ordens inferiores às evocações do núcleo central.

Nos quadrantes inferiores, temos os elementos intermediários de $2^{\mathrm{a}}$ e $3^{\mathrm{a}}$ periferia, sendo evocados entre a terceira, quarta e quinta ordem. No terceiro quadrante temos as palavras associadas ao companheirismo (3) e suporte (2). O quarto quadrante traz as palavras, sentimentos ou imagens associadas à família ideal, como: aconchego, compromisso, confiança, cumplicidade, estrutura e responsabilidade, todas representadas duas vezes.

Quadro 4 - Expressões sobre "família ideal” no pós-teste - RANGFRQ

\begin{tabular}{|c|c|c|c|c|c|}
\hline \multicolumn{3}{|c|}{ NÚCLEO CENTRAL } & \multicolumn{3}{|c|}{$\begin{array}{l}\text { ELEMENTOS INTERMEDIÁRIOS/1 } \\
\text { Periferia }\end{array}$} \\
\hline \multicolumn{3}{|c|}{$\begin{array}{l}\text { Cas ou la Fréquence }>=4 \text { et le Rang Moyen } \\
<2,6\end{array}$} & \multicolumn{3}{|c|}{$\begin{array}{l}\text { Cas ou la Fréquence }>=4 \text { et le Rang Moyen } \\
>=2,6\end{array}$} \\
\hline Amor & 13 & 2,077 & Afeto & 6 & 3,000 \\
\hline \multirow[t]{3}{*}{ União } & 4 & 2,500 & Cuidado & 4 & 4,000 \\
\hline & & & Felicidade & 4 & 3,500 \\
\hline & & & Respeito & 8 & 3,500 \\
\hline \multicolumn{3}{|c|}{$\begin{array}{l}\text { ELEMENTOS INTERMEDIÁRIOS/2a } \\
\text { Periferia }\end{array}$} & \multicolumn{3}{|c|}{$\begin{array}{l}\text { ELEMENTOS INTERMEDIÁRIOS/3a } \\
\text { Periferia }\end{array}$} \\
\hline \multicolumn{3}{|c|}{$\begin{array}{l}\text { Cas ou la Fréquence }<4 \text { et le Rang Moyen } \\
<2,6\end{array}$} & \multicolumn{3}{|c|}{$\begin{array}{l}\text { Cas ou la Fréquence }<4 \text { et le Rang Moyen } \\
>=2,6\end{array}$} \\
\hline Companheirismo & 3 & 1,000 & Aconchego & 2 & 3,000 \\
\hline \multirow[t]{5}{*}{ Suporte } & 2 & 2,000 & Compromisso & 2 & 4,000 \\
\hline & & & Confiança & 2 & 3,500 \\
\hline & & & Cumplicidade & 2 & 4,500 \\
\hline & & & Estrutura & 2 & 3,000 \\
\hline & & & Responsabilidade & 2 & 4,500 \\
\hline
\end{tabular}

Fonte: o autor.

Após a intervenção empregando o cinema como estratégia mobilizadora da experiência estética, não houve mudanças no núcleo central das representações 
sociais acerca de "família ideal”, a não ser a mera supressão da palavra diálogo, pois, no ideário coletivo, o amor aliado à união são aspectos promotores do bom funcionamento de uma família independentemente de como ela se organiza, portanto, são elementos rígidos das representações sociais. Por sua vez, nos elementos intermediários houve mudanças significativas nas evocações, sendo este um dado importante, pois esses elementos dão sustentáculo ao núcleo central das representações sociais.

O emprego da expressão indutora "família ideal" teve o intuito de verificar a presença de palavras ou sentimentos que invocassem características do modelo familiar tradicional/nuclear. Portanto, acreditávamos que no pré-teste apareceriam evocações como pai, mãe, filhos, casamento, homem e mulher, entre outros termos vinculados à "[...] idealização familiar, costumeiramente reforçada por visões psicológicas, pedagógicas, religiosas e jurídicas que favorecem a perpetuação de um ideal de família [...]" (RIBEIRO; CRUZ, 2013, p. 614). No entanto, as representações nos apontam novamente para o funcionamento familiar e não a configuração, pois, para as docentes, as famílias, independentemente das variadas configurações, podem ser funcionais. Para elas, não é a forma familiar, mas os processos familiares e a qualidade dos relacionamentos estabelecidos em seu interior que mais contribuem para processos de resistência, coesão e fortalecimento de sua unidade.

Esse dado é perceptível nas evocações obtidas no pré-teste, cujo núcleo central das evocações a partir da expressão "família ideal” se refere aos sentimentos e palavras como amor, união e diálogo, tidos como fatores basilares para a saúde da família. Após a intervenção com o uso do cinema, o resultado do pré-teste foi semelhante ao pós-teste, visto que as participantes discursaram que o ideal de família

[...] não é uma questão de laço sanguíneo e sim de afetividade, consideração, apoio e respeito [...]

Ao pensar em família, a primeira palavra que me vem à cabeça é o amor. Sendo assim, pode ser definida como Instituição do Amor.

[...] se existe amor, existe família.

Quando eu penso em família, eu penso em amor.

[...] independentemente do tipo de família, o amor e atenção deve estar sempre presente. (informações verbais).

Assim, nos momentos pré e pós-intervenção permaneceu arraigado no núcleo central das representações, a prerrogativa de que a família ideal é aquela que se 
constitui como um lócus de afeto, de felicidade, de comunhão e de amor, no qual seus membros compartilham de objetivos comuns.

\section{PARA ALÉM DA CONCLUSÃO}

À guisa da conclusão é possível apontarmos que o conceito de "família ideal", do princípio ao fim da investigação, esteve associado a valores que permitem seu bom funcionamento, como o amor, o diálogo e a união. Na concepção das educadoras, a percepção de que a família é a instituição do amor se manteve inabalada em todos os momentos da pesquisa, ou seja, o amor seria uma representação rígida, cristalizada, portanto componente do núcleo central das representações sobre o ideário de família.

Percebemos também que, para elas, o núcleo central das representações acerca de "família desestruturada" se sustentou nas brigas como um fator disfuncional, no momento pré-interventivo. Após o projeto de formação continuada foram incorporados a esse conceito outros aspectos negativos, como o desafeto e a falta de amor, que acabaram por interferir diretamente na qualidade da relação familiar, no entanto, o núcleo central manteve-se rígido em ambos os momentos.

Observamos que quando empregamos as expressões indutoras "família desestruturada" e "família ideal" detectamos mudanças nos elementos periféricos que compuseram as representações nos momentos anteriores e posteriores ao processo de formação docente. Assim, podemos afirmar, mediante os resultados obtidos por meio da aplicação dos instrumentos de ALP e do diário de campo, que a experiência estética propiciada pelo cinema e associada a outras estratégias problematizadoras é uma ferramenta capaz de (re)(des)construir conceitos quando voltada à formação de professores.

Afirmamos isso, pois o desenho metodológico que adotamos se mostrou capaz de mobilizar uma série de sentimentos, sensações, valores, expressões e opiniões condicionais acerca dos conceitos de "família ideal" e "família desestruturada", aspecto este que confere força ao cinema enquanto ferramenta capaz de afetar o contexto imediato e (re)definir representações que, quando associadas a outras estratégias, tendem a contribuir para o processo de formação docente.

\section{REFERÊNCIAS}

ABRIC, J. C. A abordagem estrutural das representações sociais. Desenvolvimentos recentes. In: CAMPOS, P. H. F.; LOUREIRO, M. C. S. (Org.). Representações sociais e práticas educativas. Goiânia: Ed. da UCG, 2003. p. 37-57. 
ABRIC, J. C. A abordagem estrutural das representações sociais. In: MOREIRA, A. S. P.; OLIVEIRA, D. C. de (Org.). Estudos interdisciplinares de representação social. Goiânia: AB, 1998. p. 27-38.

AMAZONAS, M. C. L. de A. et al. Arranjos familiares de crianças das camadas populares. Psicologia em Estudo, Maringá, v. 8, p. 11-20, 2003. Edição Especial.

ANDRADE, F. C. B. de. A teoria das representações sociais. In: SANTOS, C. S. G. dos; ANDRADE, F. C. B. de (Org.). Representações sociais e formação do educador: revelando interseções e discursos. João Pessoa: Editora Universitária, 2002. p. 17-34.

A RAZÃO do meu afeto. Direção de Nicholas Hytner. EUA: Fox Filmes, 1998. Filme (113 min).

AUMONT, J. Pode um Filme Ser um Ato de Teoria? Educação \& Realidade, Porto Alegre, v. 33, n. 1, p. 21-34, jan./jun. 2008.

BABY Love. Direção de Vincent Garenq. França: Films Distribution, 2008. Filme (99 $\mathrm{min})$.

BARCELLOS, L. V. A família homossexual vista pela jurisprudência constante. 2013. Monografia (Graduação em Direito)-Universidade Regional do Noroeste do Estado do Rio Grande do Sul, Ijuí, 2013.

BARDIN, L. Análise de conteúdo. Tradução Luís Antero Reto e Augusto Pinheiro. 4. ed. rev. e atual. Lisboa: Edições 70, 2010.

BELLA. Direção de Alejandro Monteverde. EUA; México: Califórnia Filmes, 2006. Filme (91 min).

BLASCO, P. G. et al. Cinema para o estudante de Medicina: um recurso afetivo/ efetivo na educação humanística. Revista Brasileira de Educação Médica, Rio de Janeiro, v. 29, n. 2, p. 119-128, maio/ago. 2005.

BRASIL. Constituição. República Federativa do Brasil de 1988. Brasília, DF: Senado Federal, 1988.

DE CORAÇÃO partido. Direção de Jon Gunn. EUA: Paris Filmes, 2009. Filme (104 $\min )$.

ENGELS, F. A origem da família, da propriedade privada e do Estado. Tradução Leandro Korder. 9. ed. Rio de Janeiro: Civilização Brasileira, 1984. 
FABRIS, E. H. Cinema e Educação: um caminho metodológico. Educação \& Realidade, Porto Alegre, v. 33, n. 1, p. 117-134, jan./jun. 2008.

FABRIS, E. H. Em cartaz: o cinema brasileiro produzindo sentidos sobre a escola e trabalho docente. 2005. 231 p. Tese (Doutorado em Educação)-Universidade Federal do Rio Grande do Sul, Porto Alegre, 2005.

FISCHER, S. Cotidianos no cinema brasileiro contemporâneo: imagens da família, da casa e da rua. Porto Alegre: Plus, 2009.

FRAGA, P. D. Sobre Cinema e Educação estética. Revista Espaço Acadêmico, Maringá, n. 137, p. 16-22, out. 2012.

GUIMARÃES, C. A experiência estética e a vida ordinária. Revista Eletrônica E-Compós, n. 1, p. 1-13, dez. 2004.

HINTZ, H. C. Novos tempos, novas famílias? Da modernidade à pós-modernidade. Pensando Famílias, Porto Alegre, n. 3, p. 8-19, 2001.

KEHL, M. R. Em defesa da família tentacular. Artigos e Ensaios. [S.1.], 2003. Disponível em: <http://www.mariaritakehl.psc.br/PDF/emdefesadafamiliatentacular. pdf $>$. Acesso em: 17 jul. 2014.

LACAN, J. A família. Tradução Brigitte Cardoso e Cunha, Ana Paula dos Santos e Graça Lamas Graça Lapa. 2. ed. Lisboa: Assirio \& Alvim, 1981.

LEÃO, N.; SIMAS, F.; FARIELLO, D. Veja os direitos que os homossexuais ganham com a decisão do STF. IG: Último Segundo. 2011. Disponível em: <http:// ultimosegundo.ig.com.br/brasil/veja + os + direitos + que + os + homossexuais + ganham $+\mathrm{c}$ $o m+a+d e c i s a o+d o+s t f / n 1300153607263 . h t m l>$. Acesso em: 01 set. 2014.

MENIN, M. S. de S.; ZECHI, J. A. M. Manual: conjunto de programas permitindo a análise de evocação - EVOC 2000. Presidente Prudente: Ed. Unesp, 2003.

MOSCOVICI, S. A representação social da psicanálise. Rio de Janeiro: Zahar, 1978.

MOSCOVICI, S. Representações sociais: investigações em psicologia social. Tradução Pedrinho A. Guareschi. 11. ed. Petrópolis: Vozes, 2015.

OS GAROTOS estão de volta. Direção de Scott Hicks. Reino Unido; Austrália: Califónia Filmes, 2009. Filme (103 min).

PELOS olhos de Maisie. Direção de Scott Mcgehee, David Siegel. EUA: Weinstock Productions, 2012. Filme (99 $\mathrm{min})$. 
PEREIRA, M. V. Contribuições para entender a experiência estética. Revista Lusófona de Educação, Lisboa, v. 18, n. 18, p. 111-123, 2011.

PEREIRA, R. da C. Princípios fundamentais e norteadores para a organização jurídica da família. 2004. 157 p. Tese (Doutorado em Direito)-Universidade Federal do Paraná, Curitiba, 2004.

POLETTO, M.; KOLLER, S. H. Contextos ecológicos: promotores de resiliência, fatores de risco e de proteção. Estudos de Psicologia, Campinas, v. 25, n. 3, p. 405416, jul./set. 2008 .

RIBEIRO, F. S.; CRUZ, F. M. L. Representações sociais de família por crianças na cidade de Recife. Psicologia \& Sociedade, Belo Horizonte, v. 25, n. 3, p. 612-622, 2013.

ROUDINESCO, E. A família em desordem. Tradução André Telles. Rio de Janeiro: Jorge Zahar, 2003.

SÁ, C. P. de. Núcleo central das representações sociais. Petrópolis: Vozes: 1996a.

SÁ, C. P. de. Representações Sociais: Teoria e Pesquisa do Núcleo Central. Temas em Psicologia, n. 3, p. 19-33, 1996 b.

SACRAMENTO, A. J. C. O cinema na prática pedagógica: Projeto Cine Modelo realizado no Colégio Modelo Luiz Eduardo Magalhães. 2008. Monografia (Graduação em Pedagogia)-Universidade do Estado da Bahia, Juazeiro, 2008.

SILVA, M. R. S. da et al. Processos que sustentam a resiliência familiar: um estudo de caso. Texto \& Contexto Enfermagem, Florianópolis, v. 18, n. 1, p. 92-99, jan./ mar. 2009.

SILVA, P. F. C. Olhe bem de perto: a construção dos discursos sobre a família nos filmes hollywoodianos contemporâneos. 2012. 212 p. Dissertação (Mestrado em Ciências Sociais)-Pontifícia Universidade Católica de Minas Gerais, Belo Horizonte, 2012.

SOARES, M. L. P. Educação estética: investigando possibilidades a partir de um grupo de professoras. 2008. 99 p. Dissertação (Mestrado em Educação)-Universidade do Vale do Itajaí, Itajaí, 2008.

UM DIA desses. Direção de Travis Fine. EUA: PFM Pictures, 2012. Filme (98 min). UMA LIÇÃO de amor. Direção de Jessie Nelson. EUA: Playarte, 2002. Filme (127 $\min )$. 
WAGNER, A. Os desafios da família contemporânea: revisitando conceitos. In: WAGNER, A. et al. (Org.). Desafios Psicossociais da Família Contemporânea: Pesquisas e Reflexões. 1. ed. Porto Alegre: Artmed, 2011. p. 19-35.

WALSH, F. Fortalecendo a resiliência familiar. Tradução Magda França Flores. Revisão Científica Cláudia Bruscagin. São Paulo: Roca, 2005.

YUNES, M. Â. M.; GARCIA, N. M.; ALBUQUERQUE, B. de M. Monoparentalidade, pobreza e resiliência: entre as crenças dos profissionais e as possibilidades da convivência familiar. Psicologia: Reflexão e Crítica, Rio Grande do Sul, v. 20, n. 3, p. 444-453, 2007.

Recebido em: 21 de julho de 2017 Aceito em: 10 de setembro de 2017

Endereço para correspondência: Rua Pernambuco, 858, Centro, 87701-010, Paranavaí, Paraná, Brasil; jr_oliveira1979@hotmail.com 